\title{
Erratum to: Comparative Analysis of Length of Stay and Inpatient Costs for Orthopedic Surgery Patients Treated with IV Acetaminophen and IV Opioids vs. IV Opioids Alone for Post-Operative Pain
}

\author{
Ryan N. Hansen · An Pham · Scott A. Strassels · Stela Balaban • \\ George J. Wan
}

Published online: August 25, 2016

(C) The Author(s) 2016. This article is published with open access at Springerlink.com

Erratum to: Adv Ther (2016)

DOI 10.1007/s12325-016-0368-8

During typesetting of the aforementioned article, a number of erroneous commas were inadvertently introduced into the quantities cited. Furthermore, the authors noted that the description of Fig. 2 was incorrect in the results section. As such, the following corrections should be highlighted:

In the Results section of the Abstract, the following sentence is incorrect 'We identified $4,85,895$ orthopedic surgery patients with $1,74,805 \quad(36 \%)$ who had received IV

The online version of the original article can be found under doi:10.1007/s12325-016-0368-8.

\section{R. N. Hansen $(\bowtie)$}

Pharmaceutical Outcomes Research and Policy

Program, School of Pharmacy, University of

Washington, Seattle, WA, USA

e-mail: rhansen@uw.edu

A. Pham - G. J. Wan

Mallinckrodt Pharmaceuticals, Hazelwood, MO, USA

S. A. Strassels

Optum Hospice Pharmacy Services, St. Louis, MO, USA

Present Address:

S. Balaban

United BioSource Corporation, St. Louis, MO, USA acetaminophen.' and should read 'We identified 485,895 orthopedic surgery patients with 174,805 (36\%) who had received IV acetaminophen'.

In the Results section, the following sentence is incorrect 'We identified 4,85,895 orthopedic surgery patients who were eligible for our study of which 1,74,805 (36\%) had been managed with IV acetaminophen and opioids and 3,11,090 (64\%) had been managed with IV opioids alone.' and should read as follows 'We identified 485,895 orthopedic surgery patients who were eligible for our study of which 174,805 (36\%) had been managed with IV acetaminophen and opioids and 311,090 (64\%) had been managed with IV opioids alone'.

Also in the Results section, the following sentence is incorrect 'Subgroup analyses by surgery type revealed that LOS was consistently lower across all surgery groups, though only the fracture and other subgroups were statistically significantly lower. These subgroup analyses also showed that while costs were estimated to be lower for most groups, they were slightly higher for total knee replacements and other surgeries, none of 
Table 1 Demographic characteristics of orthopedic surgery patients, comparing IV acetaminophen (Ofirmev) recipients to IV opioid monotherapy recipients

\begin{tabular}{|c|c|c|}
\hline Characteristic & IV opioids $(n=311,090)$ & IV acetaminophen $(n=174,805)$ \\
\hline Age (years), mean (SD) & $64.3(15.6)$ & $63.6(14.0)$ \\
\hline Female, $n(\%)$ & $179,779(57.8)$ & $102,864(58.8)$ \\
\hline \multicolumn{3}{|l|}{ Race, $n(\%)$} \\
\hline White & $238,421(76.6)$ & $140,748(80.5)$ \\
\hline Black & $24,876(8.0)$ & $14,591(8.4)$ \\
\hline Hispanic & $47,600(15.3)$ & $19,362(11.1)$ \\
\hline Unknown & $193(0.1)$ & $104(0.1)$ \\
\hline \multicolumn{3}{|l|}{ APR-DRG severity of illness, $n(\%)$} \\
\hline Minor & $136,264(43.8)$ & $80,801(46.2)$ \\
\hline Moderate & $130,231(41.9)$ & $77,862(44.5)$ \\
\hline Severe & $36,973(11.9)$ & $14,462(8.3)$ \\
\hline Extreme & $7622(2.5)$ & $1680(1.0)$ \\
\hline \multicolumn{3}{|l|}{ APR-DRG risk of mortality, $n(\%)$} \\
\hline Minor & $217,279(69.8)$ & $137,283(78.5)$ \\
\hline Moderate & $63,080(20.3)$ & $28,648(16.4)$ \\
\hline Severe & $24,654(7.9)$ & $7454(4.3)$ \\
\hline Extreme & $6077(1.9)$ & $1420(0.8)$ \\
\hline Elective surgery, $n(\%)$ & $210,663(67.7)$ & $136,318(78.0)$ \\
\hline \multicolumn{3}{|l|}{ Hospital region, $n(\%)$} \\
\hline Midwest & $60,685(19.5)$ & $27,639(15.8)$ \\
\hline Northeast & $70,154(22.6)$ & $28,530(16.3)$ \\
\hline South & $132,013(42.4)$ & $104,113(59.6)$ \\
\hline West & $48,238(15.5)$ & $14,523(8.3)$ \\
\hline \multicolumn{3}{|l|}{ Surgery type, $n(\%)$} \\
\hline Total knee replacement & $66,725(21.4)$ & $64,399(36.8)$ \\
\hline Total hip replacement & $40,140(12.9)$ & $33,541(19.2)$ \\
\hline Knee revision & $5187(1.7)$ & $4869(2.8)$ \\
\hline Hip revision or partial replacement & $26,672(8.6)$ & $9671(5.5)$ \\
\hline Fracture & $64,395(20.7)$ & $17,928(10.3)$ \\
\hline Other $^{\mathrm{a}}$ & $107,971(34.7)$ & $44,397(25.4)$ \\
\hline
\end{tabular}

$A P R-D R G$ all patient refined-diagnosis related group, $I V$ intravenous, $S D$ standard deviation

${ }^{a}$ Shoulder and spine 
Table 2 Unadjusted outcomes of orthopedic surgery patients, comparing IV acetaminophen recipients to IV opioid monotherapy recipients

\begin{tabular}{|c|c|c|c|c|}
\hline Outcome & $\begin{array}{l}\text { IV opioids } \\
(n=311,090)\end{array}$ & $\begin{array}{l}\text { IV acetaminophen } \\
(n=174,805)\end{array}$ & Difference (95\% CI) & $P$ value \\
\hline $\begin{array}{l}\text { Length of stay (days), mean } \\
\text { (SD) }\end{array}$ & $3.9(3.9)$ & $3.2(2.6)$ & $-0.66(-0.68$ to -0.64$)$ & $<0.0001$ \\
\hline $\begin{array}{l}\text { Hospitalization cost }(\$) \text {, mean } \\
\quad(\mathrm{SD})\end{array}$ & $19,927.6(19,578.8)$ & $19,024.9(13,113.7)$ & $-902.7(-1005.4$ to -800.0$)$ & $<0.0001$ \\
\hline $\begin{array}{l}\text { Morphine equivalent dose } \\
(\mathrm{mg}) \text {, mean }(\mathrm{SD})\end{array}$ & $43.8(53.4)$ & $46.9(44.5)$ & $3.1(2.8$ to 3.4$)$ & $<0.0001$ \\
\hline \multicolumn{5}{|c|}{ Opioid-related AEs, OR ${ }^{\mathrm{a}}(95 \% \mathrm{CI})$} \\
\hline Urinary tract infection & & $0.596(0.56$ to 0.63$)$ & & $<0.0001$ \\
\hline Respiratory depression & & $0.518(0.50$ to 0.54$)$ & & $<0.0001$ \\
\hline Surgery site infection & & $0.754(0.71$ to 0.80$)$ & & $<0.0001$ \\
\hline Bowel obstruction & & $1.013(0.99$ to 1.04$)$ & & 0.4 \\
\hline Nausea/vomiting & & $1.208(1.16$ to 1.26$)$ & & $<0.0001$ \\
\hline
\end{tabular}

$A E$ adverse event, $C I$ confidence interval, $O R$ odds ratio, $I V$ intravenous, $S D$ standard deviation

${ }^{a}$ IV opioid monotherapy is the reference group

which were statistically significantly different. Opioid dose was also lower for all groups (non-significant with the exception of other) except MED was slightly higher for knee revisions (1.1 mg, $P=0.8$; Fig. 2).' And should read as follows 'Subgroup analyses by surgery type revealed that LOS was statistically significantly lower for all groups with the exception of knee revision. These subgroup analyses also showed that while costs were estimated to be lower for most groups, they were slightly higher for total knee replacements and other surgeries, neither of which were statistically significantly higher. Opioid dose was also lower for all groups except MED was slightly higher for knee revisions $(1.1 \mathrm{mg}, P=$ 0.8; Fig. 2)'.

A number of errors were noted in Table 1. Table 1 should appear as above.
Furthermore, errors were noted in the field headings of Table 2 . Table 2 should appear as above.

\section{OPEN ACCESS}

This article is distributed under the terms of the Creative Commons Attribution-NonCommercial 4.0 International License (http://creative commons.org/licenses/by-nc/4.0/), which permits any noncommercial use, distribution, and reproduction in any medium, provided you give appropriate credit to the original author(s) and the source, provide a link to the Creative Commons license, and indicate if changes were made. 